Synthesis of Natural

Products and

Potential Drugs

\title{
Total Synthesis of (+)-Ryanodol
}

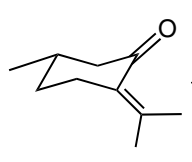

(S)-Pulegone
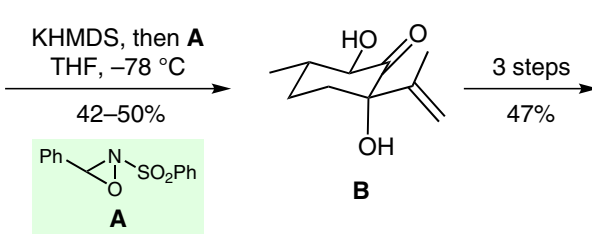

B

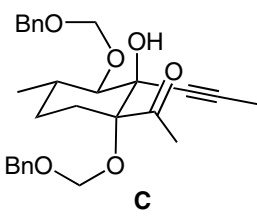

$68 \%$

1. D, THF, $0^{\circ} \mathrm{C}$

$\mathrm{PhMe}, 0^{\circ} \mathrm{C}$

$\mathrm{EtO}=\mathrm{MgBr}$
2. AgOTf $(2 \mathrm{~mol} \%)$

Key words

(+)-ryanodol

(+)-anhydroryanodol

Pauson-Khand reaction

reductive

cyclization

selenium dioxide oxidation

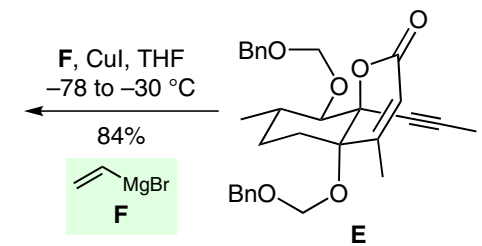

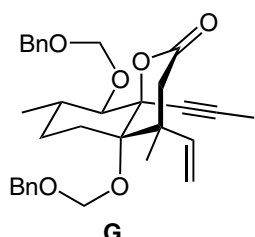
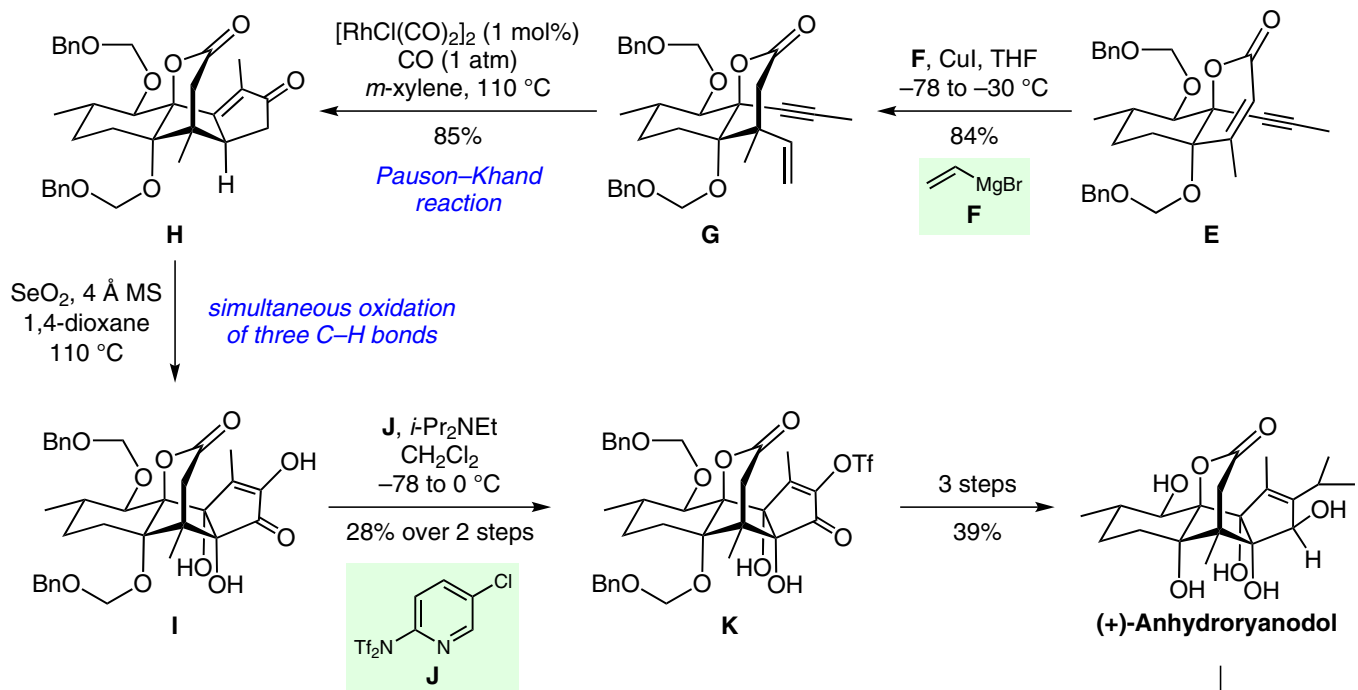

(+)-Anhydroryanodo

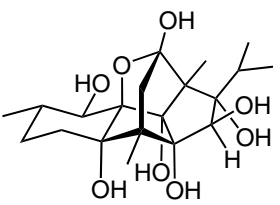

1. $\mathrm{CF}_{3} \mathrm{CO}_{3} \mathrm{H}, \mathrm{Na}_{2} \mathrm{HPO}_{4}$

1,2-DCE

2. $\mathrm{Li}, \mathrm{NH}_{3} / \mathrm{THF},-78{ }^{\circ} \mathrm{C}$

$33 \%$ over 2 steps

(+)-Ryanodol

Significance: (+)-Ryanodol is a highly oxidized complex diterpenoid and the hydrolysis product of ryanodine. It modulates intracellular $\mathrm{Ca}^{2+}$ channels, albeit with lower affinity than the parent natural product. Reisman and co-workers completed the synthesis of (+)-ryanodol in only 15 steps from (S)-pulegone.
Comment: Key intermediate $\mathbf{G}$ was assembled in seven steps from (S)-pulegone and transformed into enone $\mathbf{H}$ by a highly diastereoselective

Pauson-Khand reaction. Treatment of tetracycle $\mathbf{H}$ with $\mathrm{SeO}_{2}$ under strictly anhydrous conditions led to the simultaneous installation of three oxygen functionalities. (+)-Anhydroryanodol was finally converted into (+)-ryanodol by epoxidation and reductive cyclization.

SYNFACTS Contributors: Erick M. Carreira, Nicole Hauser 